\title{
El periodista diluido
}

\section{Diluted Journalist}

Javier Galán Gamero. Universidad Carlos III de Madrid

\section{Resumen:}

Que los medios de comunicación están crisis, que la propia actividad periodística está en crisis, que los propios fundamentos del periodismo están crisis, es algo más que evidente y ha sido puesto de manifiesto, desde distintos puntos de vista, por diversos autores, tanto académicos, como profesionales del periodismo, llegando a un consenso más o menos explícito de que esta crisis no es coyuntural, una más de la que han padecido los medios a lo largo de su historia, sino estructural y que puede llevar a la desaparición de la propia profesión, al menos tal y como la conocemos hasta ahora. La intensidad de dicha crisis, los motivos que la han generado y, en especial, las posibles soluciones a la misma es en lo que ya no existe un tan amplio consenso. En este artículo pretendemos analizar los orígenes y razones de dicha crisis, definir un diagnóstico y, en la medida de lo posible, aportar soluciones a la misma o, al menos, abrir algunas puertas para la esperanza y recuperación de una actividad esencial para la convivencia social.

Palabras clave:

Periodismo, profesión periodística, medios de comunicación, ética profesional.

\section{Abstract:}

That the media is crisis, journalism itself is in crisis, that the very foundation of journalism is a crisis, is more than evident and has been shown from different viewpoints by different authors, both academic, as journalism professionals, reaching a more or less explicit consensus that this crisis is not temporary, one more than the media who have suffered throughout their history, but structural and can lead to the disappearance of one's own profession, at least as we know it. The severity of this crisis, why it has generated and, in particular, possible solutions to it is what no longer exist such a broad consensus. In this paper we analyze the origins and reasons for the crisis, to define a diagnosis and, as far as possible solutions to the same or at least open some doors for hope and recovery of an essential activity for coexistence social.

Keywords:

Journalism. Journalistic profession. Media. Professional ethics. 


\section{Introducción}

Los medios de comunicación tradicionales, prensa, radio y televisión, sin dejar de lado la agencias, están experimentando una crisis que, lejos de ser una más de las experimentadas a lo largo de su existencia, se está manifestado como una crisis estructural que no sólo hace que se tambalee el actual sistema de medios, sino que también pone en entredicho la propia misión de cada uno de ellos. Como consecuencia de la misma, la actividad periodística acusa que los principios que la sustentan se tambalean y los propios periodistas advierten que su identidad profesional se diluye entre nuevos quehaceres.

Las causas de esta crisis son múltiples pero se podrían agrupar en tres grandes corrientes. Quizá la más importante o, al menos la más significativa, es el impacto que han tenido y tienen las aplicaciones a la comunicación de los nuevos avances tecnológicos. También han influido, de manera considerable, las tendencias surgidas en las últimas décadas en las configuraciones empresariales de los medios tradicionales. Y, por último, también han contribuido como acelerador de la misma, los cambios de percepción que, sobre el periodismo, se han experimentado en la sociedad.

Una de las consecuencias de esta crisis es la pérdida de identidad profesional del propio periodista que se ve abocado a dedicar la mayor parte de su jornada laboral a quehaceres tecnológicos y no a quehaceres informativos; a primar los intereses comerciales, sobre los intereses sociales; a convertir la información en espectáculo; a bregar con mayor intensidad con informaciones oficiales, políticas y no políticas, cada vez más opacas; a competir con quienes ponen en circulación información elaborada sin criterios de calidad, pero que califican de periodística, etc. Actividades que no solo no tienen nada que ver con las propias de una consolidada profesión periodística, sino que incluso son contrarias a la misma.

Esta situación lleva a plantearse si el periodismo entra en una nueva etapa, que rompe con la anterior y es necesario reconfigurar los fundamentos de la profesión o, si por el contrario, lo que hay que hacer es aprender de los errores cometidos, y reconfigurar las actividades periodísticas de acuerdo con los fundamentos periodísticos acrisolados durante siglos. Para Nobre-Correira (2006) "la evolución global del sistema mediático parece indicar que se está ante una crisis, cada vez más acentuada, de la concepción del periodismo que nació en el transcurso del siglo XIX o incluso, que tal concepción está entrando en una especie de coma irreversible. De hecho, ahora, los medios de comunicación que cubren la actualidad se basan en criterios que ya no son los del servicio prestado a los ciudadanos para facilitar su integración en la sociedad, la asunción de su papel de ciudadano en un sistema democrático. Lo que se busca ahora es proporcionarles la dosis de sueño y de juego necesaria para que puedan afrontar las obligaciones, las tensiones, el estrés y las angustias de su vida diaria, profesional y familiar, aunque también para llevarles a asumir plenamente y con alegría su papel de consumidores". 


\section{El impacto de los avances tecnológicos en el quehacer informativo}

Es evidente que la aplicación de los avances tecnológicos a la comunicación ha tenido y tiene un importante impacto en el quehacer periodístico. Por una parte facilita el acceso a la información, interesante y de actualidad, que ofertan las fuentes "oficiales", tanto para el periodista como para el resto de los ciudadanos interesados en ella; por otra, se ofrecen también múltiples herramientas para producir esa información, de tal manera que ya no es necesario contar con estructuras demasiado complejas o demasiado caras para convertirla en producto. En este sentido se favorece que se incremente el número de entidades, a veces personas solas, que elaboran información y la ofertan al mercado; y, en tercer lugar esos nuevos avances tecnológicos, multiplican las posibilidades de difusión de dichas informaciones. Baldessar (2007: 114) se hacía este planteamiento: "La constatación de que el periodismo está pasando por transformaciones profundas y que muchas de sus prácticas se encuentran en proceso de renovación, puede ser cotejada si aceptamos que el mundo en red y digital está reconfigurando las relaciones y las prácticas profesionales y alterando las rutinas de recolección, procesamiento y difusión de la información”.

Esos avances tecnológicos plantean dos cuestiones de fondo. La primera de ellas es si van a transformar en su estructura los medios tradicionales e incluso que vayan a propiciar su desaparición y, la otra, es si van a afectar, y en qué manera, a la propia actividad periodística según la venimos comprendiendo históricamente.

Para Canga (2001: 39) "la aparición del Nuevo Medio no supone forzosamente la desaparición de los ya existentes, sino la necesidad de complementarse. Es por eso que considero que los medios clásicos, fundamentalmente la prensa, seguirán existiendo y volverán a adaptarse a las nuevas circunstancias como lo han hecho en el pasado. No obstante, la aparición y consolidación de Internet como nuevo medio de comunicación ha vuelto a poner sobre la mesa el tema recurrente de la desaparición de la Prensa. Y de nuevo, como tantas veces en el mundo de la información/comunicación, suenan las voces tanto de los apocalípticos como de los integrados". Con esos dos calificativos apocalípticos e integrados se define claramente las dos corrientes que se perfilan sobre los cambios estructurales de los medios. Los diarios en papel ¿desaparecen o no desaparecen?; la televisión generalista ¿deja de existir o se mantiene?; la radio, ¿qué va a pasar con la radio?; ¿ ¿las agencias de noticias, no se convertirán en las auténticas protagonistas en la generación de información que luego se distribuirá por multicanales?; ¿las redes sociales se van a convertir en el medio tradicional para recibir información?, etc.

Ha pasado muy poco tiempo y la implantación de los avances tecnológicos -los ya conocidos y los que faltan por aparecer- aún no se ha generalizado lo suficiente como para proyectar a futuro, con una cierta solvencia, la muerte y destrucción de los tradicionales medios de comunicación. 
Además, esas reformas estructurales de los medios también van a depender mucho de las configuraciones empresariales que los sustentan y de las propias respuestas que esos medios den a la asimilación de la tecnología. Lo importante es determinar si los adelantos tecnológicos van a influir en la propia concepción de la actividad periodística. Como señala Baldesaar (2007: 116), "para estudiosos como Garrison (1993) y Reddick/King (1995) el propio concepto de periodismo podrá modificarse debido a varios factores, entre ellos: (1) la posibilidad de cada uno de actuar como periodista, disponiendo contenidos en Internet; (2) la usurpación al periodista de la función de gatekeeper, privilegiando el espacio público informativo; (3) las características propias de Internet, que permiten el aprovechamiento de la hipermedia (la confluencia de varios medios de comunicación masiva en uno solo) y de los hiperenlaces -hiperlink- (los links que permiten la navegación en Internet) y claro, las innumerables posibilidades de interacción con el público".

Lo profundo de esos cambios -que van a producirse, a corto o a la largo plazo- en el concepto de la actividad periodística va a depender de muchos factores. La propia tecnología, que va a obligar a una denominación o redenominación de la actividades periodísticas, como señala Arriaza (2008: 5): "A medida que nuevas plataformas mediáticas emergen casi instantáneamente y los medios públicos se adentran en nuevos formatos, surgen dudas e incluso problemas que antes no habían sido considerados. La radio que se escucha en un teléfono móvil o en un podcast, ¿̇igue siendo radio? La televisión interactiva por Internet o en otras redes digitales, ¿continúa siendo televisión, especialmente si nos referimos al servicio público tradicional que prestan los medios? Adicionalmente, ¿qué ocurre con las noticias y demás servicios que ofrece Internet? ¿Qué clase de valores profesionales deberían guiar a los profesionales de los medios en estos nuevos soportes? ¿Debería intervenir el Estado en la Red tal como lo hizo durante el establecimiento de los servicios públicos de información en su momento?” Planteamientos a los que hay responder desde la propia profesión periodística, porque en esta nueva conceptualización va a ser necesario adentrarse en los elementos fundamentales que sustentan los principios de la actividad periodística que si bien se daban por definidos, la propia práctica de la profesión está poniendo en duda. En este sentido, señala Ortega (2003) que "un periodista tan agudo como Indro Montanelli percibía con claridad este cambio del oficio al describirse a sí mismo, en su obra póstuma, como "sólo periodista" (soltanto un giornalista), para diferenciarse del periodismo actual, sobrecargado de tareas múltiples en las que no siempre la principal es la labor informativa”.

Ya hace unos años, Hallin (1997: 125) señalaba que "resulta correcto, sin embargo, afirmar que la profesionalización (de la actividad periodística) estaba en su mayor parte consolidada, no obstante, hacia la mitad de los años cuarenta, cuando la Comisión para la Libertad de Prensa preparaba su informe. Durante los años transcurridos de entonces ahora, la mayoría de los periodistas y de los analistas de los medios esta- 
dounidenses llegaron a considerar este modelo de periodismo como estable y permanente; el producto final de una 'evolución histórica natural' del periodismo. Ahora, en cambio, parece que tendríamos que preguntarnos si la era del profesionalismo ha demostrado ser una breve y más bien anómala fase; un periodo ocupado por poco más de una generación, cuando las contradicciones entre los diferentes roles asumidos por los medios informativos en el terreno económico, político y cultural, parecían resueltas, siendo sólo así de una forma temporal e ilusoria. No es probable que el modelo profesionalizado de periodismo desaparezca de la escena por completo. Está demasiado arraigado en la cultura como para que eso ocurra. [...] Sin embargo, no es probable que el profesionalismo mantenga su autoconfianza respecto a su propia identidad y su dominio sobre la escena mediática estadounidense, de los que disfrutó durante las pasadas una o dos generaciones".

Tengamos en cuenta que estas afirmaciones se hacían antes de que los nuevos avances tecnológicos se implantaran con la intensidad con que están implantados en la actualidad. En la actualidad la crisis se ha agudizado y como señala Almirón (2006): “La cuestión que se plantea es, pues, si las nuevas tecnologías de la información y la comunicación (TIC) provocan y/o aceleran esta crisis de valores de la profesión periodística o si, por el contrario, constituyen un aliado valioso para luchar contra ella. La cuestión que, en definitiva, se pretende aclarar es si la convergencia digital motiva el debilitamiento de los elementos esenciales del periodismo o si, por el contrario, los fortalece”.

A este respecto hay quien como Baldessar (2007: 115) considera que el impacto de las tecnologías no tiene por qué afectar a los criterios de actividad periodística ya que "el Periodismo siempre tuvo su quehacer diario ligado a la tecnología. A cada nuevo invento la profesión modifica sus prácticas, desarrolla lenguajes, crea nuevas formas de mostrar el mundo a través de la información. La asimilación de ese hecho facilita vislumbrar el profesional necesario para la actualidad: un profesional que cumpla las actividades periodísticas tradicionales, pero que utilice Internet y el mundo en red como herramienta cotidiana”.

No obstante hay otros que consideran que esas nuevas tecnologías afectan con mayor intensidad la actividad periodística. Martínez (2005) sostiene que "el periodista es un periodista en transformación, porque la Red está en continua evolución. En el perfil del periodista del siglo XXI convergen viejas y nuevas rutinas, a los tradicionales criterios de selección, jerarquización, interpretación, se unen destrezas como la gestión de contenidos o la dinamización de las relaciones que fluyen por el ciberespacio. Entre las facetas que componen el perfil del comunicador digital, en este texto reivindicamos la función del periodista como periodificador, es decir, como "ordenador de contenidos" y "clasificador de la realidad", donde los nuevos criterios de selección y valoración de contenidos serán las dos operaciones básicas”. 
En esta concepción quedan atrás, aunque no eliminadas, las clásicas tareas del periodista como obtener información, elaborarla y transmitirla a través de diversos canales. Ello pone de manifiesto que, al menos, se está cuestionando las funciones básicas del periodismo. En esta misma concepción se deja claro que la implantación de los avances tecnológicos está haciendo replantearse los principios que rigen la actividad periodística. Los periodistas son quienes sufren estos cambios y, unos con mayor intensidad, otros con menos, se plantean su profesión y mientras tanto se diluyen en un mar de dudas sobre qué es lo que están haciendo y si lo que están haciendo responde a los fundamentos que les llevaron a optar por esta profesión.

\section{El proceso de transformación empresarial}

Al mismo tiempo que los avances tecnológicos afectan a la estructura de la profesión periodística, hay otro factor que también la está impactando, incluso con mayor fuerza. Las estructuras empresariales que sustentaban la organización de esta actividad han cambiado considerablemente su gestión, tanto que, ganar dinero se ha convertido en la actividad primordial de las mismas, dejando al margen cualquier objetivo de responsabilidad social. Esto produce un cambio cualitativo considerable en el propio modelo de empresa informativa, porque lo que plantea no es un mero cambio organizacional o de gestión; lo que plantea es un profundo cambio en la misión, en la razón de ser de esas empresas.

Entre otras cosas, señala Almirón (2006), esto se debe a que "el modelo económico de organización dominante que se ha impuesto a lo largo del siglo XX en la industria de la comunicación tiende a lo que los estadounidenses denominan el corporate media (McChesney, 2005; Artz y Kamalipour, 2003), la integración de los medios de comunicación en corporaciones de enormes dimensiones cuyas actividades principales se realizan crecientemente en sectores distintos al de la comunicación". Ramonet (2005) describe esta situación referida también a Europa: "La crisis tiene también causas internas, que obedecen principalmente a la pérdida de credibilidad de la prensa escrita. En primer lugar porque esta pertenece cada vez más a grupos industriales que controlan el poder económico y que están en connivencia con el poder político. Y también porque la parcialidad, la falta de objetividad, la mentira, las manipulaciones o simplemente las imposturas, no cesan de aumentar. Sabemos que no ha existido ninguna época dorada de la información, pero actualmente esas derivas han alcanzado también a los diarios de calidad".

Esta nueva configuración empresarial, en la que en muchas ocasiones los propietarios de los medios de comunicación son empresas que nada tienen que ver con la información periodística, conlleva a que la principal finalidad de los medios de comunicación sea la obtención de beneficios económicos, dejando al margen cualquier fin social, porque se deben más a sus accionistas, a la bolsa, que a sus ciudadanos, y toda 
la gestión prioriza más la obtención de resultados económicos que la obtención de bienes sociales. El periodista, desde la empresa a que pertenece, se siente presionado en este sentido, le provoca una considerable crisis de principios y le diluye en un mar de dudas sobre si lo que está haciendo, lo que le imponen que haga, tiene algo que ver con su profesión de periodista.

Las empresas periodísticas nacieron de la mano de las empresas editoras: de libros, de folletos, de panfletos, etc. Las empresas periodísticas tardarán años, siglos, en independizarse de los impresores y en encontrar su propia identidad empresarial. Se dará esa circunstancia cuando se tenga un producto diferente, adaptado a los mercados y rentable, aunque solo fuera para mantenerse en la actividad. Los periódicos, los diarios, fueron esos productos. Las empresas periodísticas tuvieron su auge cuando los diarios eran la estrella de la información en la sociedad. Eran empresas auténticamente periodísticas, ellas acrisolaron el nombre, y no solo porque se dedicaran a editar periódicos sino porque producían información que ayudaba a la sociedad a comprender el mundo en el que vivía y, de alguna manera, la hacía más libre.

Es en esos momentos en los que la función social de la actividad periodística está más clara y evidente. La actividad periodística se une inexorable a la función social, a los derechos fundamentales. La parte comercial quedaba en un segundo término. Se decía con orgullo aquello de que "periodista que muere rico, muere deshonrado”. La razón de ser de las empresas periodísticas está más en la defensa de las libertades que en la obtención de beneficios económicos. Los periodistas asumían esa misión, pero la empresa también, y todo el modelo de gestión se aplicaba más a realizar la misión social que a la obtención de beneficios, ya fuesen económicos o políticos. Modelo de gestión que llevó a la quiebra a más de una de esas empresas, pero fueron muertes honrosas, dignas y gloriosas.

Pero, como señala Hallín (1997: 128), "desde 1970, a medida que los periódicos que en otro tiempo fueron negocios de propiedad familiar fueron vendidos a cadenas o salieron por sí mismos a la búsqueda de la financiación indeterminada de la Bolsa, se fueron gradualmente acomodando a las expectativas de Wall Street y, al hacerlo, el ideario del periodismo de servicio público -según la teoría de los accionistas-, fue paulatinamente dejado de lado. Los propietarios de periódicos tradicionales querían ganar dinero, por supuesto. Pero solían sentirse satisfechos con márgenes de entre el 5 y el 7 por ciento y estaban fuertemente motivados por el prestigio y la consideración pública de sus diarios. Fue en ese contexto económico, según esta línea de interpretación, donde el profesionalismo periodístico prosperó. Con Wall Street marcando la pauta no está claro que pueda sobrevivir".

En paralelo a esta transformación del modelo de la estructura financiera de los diarios, se producía un cambio importante en cuanto a los contenidos. La prensa amarilla dio un primer aviso. Productos semejantes, 
a los diarios consolidados, ofrecían pingües beneficios a sus empresas editoras. Ahora bien, este tipo de prensa, ¿podía considerarse como defensora de los derechos sociales? Con este tipo de prensa se inició un cambio de criterio que, a la postre, se ha manifestado como nefasto: esos diarios no ofertaban lo que la sociedad debía saber, sino lo que a la sociedad le gustaba saber. Fue el primer paso, luego vinieron la radio y la televisión.

La radio primero y luego la televisión, con mayor intensidad, siendo considerados, igual que la prensa, como medios de comunicación, han transformado la mayoría de sus contenidos informativos en divertimento. Y con ellos comienza el espectáculo. Un espectáculo que impregna toda la programación televisiva, incluidos sus espacios informativos, como dice Mateos-Pérez (2009:334) referido a España: "La llegada de las televisiones privadas supuso el nacimiento de una nueva era para los programas informativos. Los nuevos contenidos, espectaculares, sensacionalistas y valorativos, fundaron un nuevo modelo informativo mercantil, que entretuvo, más que informó, a la audiencia”. Espectáculo que se exporta a los otros medios. Dice Labio (2008: 436) que "la contaminación del sector audiovisual afecta a la prensa diaria, que asume como propia la tendencia hacia contenidos más del gusto de un público mayoritario. Se intenta así combinar el análisis político con la sección de personajes famosos, la información deportiva con los escándalos que rodean a ciertos futbolistas o la cultura con la fotografía de una modelo ataviada con transparencias. Se trata de una combinación extraña y desconcertante para el lector habitual de periódicos de referencia que, a ratos, puede sentirse confundido sobre el tipo de publicación ante la que se encuentra”. De tal manera que "puesto en cuarentena el objetivo de formar, cabe preguntarse si la tarea periodística se limita actualmente sólo a entretener. La respuesta, aunque cueste reconocerlo, parece ser afirmativa”.

A estos factores, -cambio de misión, cambio de modelo financiero y cambio de contenidos- hay que añadir el del fenómeno de la convergencia empresarial. Es raro el medio de comunicación que permanece independiente de grupo empresarial. La tendencia es la creación de grandes grupos mediáticos donde se aglutinan medios de comunicación con empresas de otro tipo, relacionadas o no con el mundo de la comunicación.

Este agrupamiento de medios ha traído una consecuencia directa y concreta para el periodista, lo que se viene denominando la convergencia de las redacciones. De tal manera que un periodista no trabaja para un medio: trabaja para un grupo de medios.

A este respecto, señala Salaverría (2008: 41) que "en los estudios sobre la convergencia de medios, se muestra una creciente preocupación entre los periodistas, porque perciben que genera ansiedad, tensión y saturación de trabajo (Deuze, 2004). Los redactores multimedia acumulan más presiones a las ya tradicio- 
nales, aunque saben que la convergencia no es un problema en sí misma. Singer (2006) señala que los periodistas se preocupan por el deterioro de la calidad, por la independencia y por las decisiones editoriales de los contenidos que se publican.

En ocasiones, los periodistas en la redacción integrada constatan que su labor se reduce a "re-empaquetar" la información de prensa o audiovisual en vez de cubrir sus propias informaciones; lo que genera cierto sentimiento de frustración. Asimismo, la convergencia incrementa el riesgo de la homogeneización en los contenidos, ya que favorece que las informaciones, e incluso el estilo de los medios, se parezcan entre sí cada vez más”.

Una vez más el periodista se diluye en una estructura organizativa que entre otras cosas le impide pensar, tener presente, a la hora de elaborar la información, al público que va a ser receptor de la misma. El periodista pierde la referencia de los receptores, entre otras cosas porque no sabe qué canal utilizará para difundir su información. Y, por tanto, los receptores pierden la referencia del periodista.

Concluye Salverría (2008: 45) que "los condicionantes de la producción informativa en el entorno de convergencia (actualización constante, adaptación a múltiples soportes, sobrecargas de trabajo, etc.) pueden incidir en el debilitamiento de estándares periodísticos tales como la veracidad, la exactitud y el rigor. Por ello, hay que considerar en qué medida, a pesar de las ventajas que la convergencia de redacciones traiga consigo, la calidad de los contenidos periodísticos puede disminuir significativamente".

\section{La superabundancia de información opaca}

Desde que Eve L. Lee publicara su manifiesto, las empresas, las instituciones y la política, de una manera especial, han recorrido un largo camino en su relación con los medios de comunicación. En unos primeros momentos estas relaciones fueron muy frías, distantes y se entendía que la mejor relación era no tener relación. Después descubrieron que los medios de comunicación eran menos peligrosos si las relaciones con ellos eran fluidas y amables. En una tercera etapa, se produce el descubrimiento de que los medios de comunicación son una pieza útil para la consecución de sus fines y, por último, entiende que los medios son una pieza imprescindible en sus estrategias comerciales. La política recorrió estas etapas de manera más rápida que el mundo empresarial, y ya desde que la prensa apenas estaba en sus inicios era utilizada para difundir ideas políticas que pudieran inducir a la consiguiente acción. En la actualidad, señala Nobre-Correia, (2006), “como consecuencia de la evolución de los mundos político, económico, social, cultural y deportivo, el resultado de los desafíos a los que estos se enfrentan depende mucho de la estrategia de co- 
municación de sus actores, empresas e instituciones. Por lo que el ejercicio de su influencia sobre los periodistas solo puede acrecentarse. Y los periodistas estarán confrontados con una contradicción insostenible: para obtener información original, "exclusiva”, tendrán que codearse con gente de aquellos mundos, con lo que darán pábulo a toda clase de instrumentalizaciones, connivencias y arreglos”.

El elemento interesante que los medios de comunicación ofrecen a las empresas e instituciones, y a la política, es su capacidad de mantener una relación con una gran cantidad de mercado, a un coste no excesivo, y con un alto grado de persuasión. Lo que constituye una herramienta precisa para vender o para defender sus productos en amplios mercados. Herramienta de la que no pueden prescindir, tal y como está establecido el sistema social de comunicación, ni los políticos, ni las empresas, ni las instituciones de una cierta relevancia. Y no nos referimos exclusivamente a la publicidad. "A las empresas no les bastaba con la intervención a través de la publicidad. También intentaron intervenir en la recogida de información, suministrando a los periódicos la "información” y los "análisis" que deseaban que se publicasen como si fuesen artículos de la redacción. Los dirigentes, sobre todo los políticos, pero también los sindicatos y las asociaciones, se inspiraron en tal modo de proceder (Delporte, 1995 y 1999). Ante la avalancha de escritos diversos, enviados por empresas, instituciones y asociaciones, que invadió las redacciones, los periodistas dejaron a menudo de realizar unas tareas esenciales, tales como la verificación de los elementos fácticos y su ubicación en el contexto".

Y hubo medios, hay medios, hay periodistas (salvo honrosas excepciones) que han caído en la trampa de convertir su actividad profesional en una mera tarea de adecuación de la información que les llega a los dispositivos técnicos del soporte. A esto ha ayudado, sin lugar a dudas, la fuerte presión que recibe el periodista para producir información al menor coste posible y el que los medios hayan dejado de ser independientes y se hayan convertido en una pieza más de un conglomerado empresarial y político, cuyos fines prioritarios no son la información sobre el acontecer social, ni el ofertar una información a los ciudadanos que les ayude a comprender el mundo en el que viven. También ha propiciado esta situación, la mejora de la calidad e intensidad mediática de la información que se ofrece desde las fuentes oficiales. Para Diezhandino (2005), "el inmenso flujo de información que reciben las redacciones está abriendo un espacio importante al viejo peligro de servir, no al público, sino a los creadores de noticias (newsmakings); en lugar de controlar al poder establecido, lo apuntalan. Eligen, pero no seleccionan (...) Y todo ello tiene que ver con lo que la UNESCO ya apuntaba: la desprofesionalización del oficio del periodista, que se va convirtiendo en un simple recadero de despachos o imágenes recibidos a través de las redes, estandarización de los contenidos de la información y tratamiento sensacionalista y espectacular de las imágenes. Otros tan- 
tos fenómenos que socavan la credibilidad de la información y provocan una crisis de confianza en el público y de desconcierto en los propios periodistas".

Esta superabundancia de información opaca que en la actualidad ofrecen los medios conlleva una lógica pérdida de confianza por parte de los ciudadanos que perciben que los medios de comunicación no están a su servicio, sino que están al servicio de sus propios intereses. Respecto a España, Ortega (2007) dice: "El aparente ropaje del poder y la influencia con el que suele recubrirse una parte importante del periodismo español actual, esconde una realidad que puede acabar por subvertirlo desde dentro, convirtiéndolo en una institución con escaso prestigio, poco crédito y un recorte apreciable de recompensas, ya sean éstas materiales o simbólicas. Y, sin embargo, hace menos de un lustro los presagios eran los contrarios. El creciente e imparable estatus que había venido ganando la profesión a partir de la transición, y el no menor auge de su protagonismo en los escenarios públicos parecían no tener límites. Ante la ausencia de competidores eficaces en el sistema de producción y distribución de conocimiento social, el periodismo se había erigido en la principal fuente de referencia social y cultural. Y todo ello había redundado en la adquisición de sustanciosos recursos y medios de intervención e influencia en múltiples ámbitos, particularmente en la política”.

Esta crisis de la actividad periodística hace que el propio periodista pierda su identidad. En palabras de Canel (1999: 17), "esta confusión, que podemos llamar paradoja o distancia entre lo que los periodistas consideran el deber ser de su profesión y lo que realizan en la práctica, pone de manifiesto que hay algunas cuestiones sobre la profesión periodística que están todavía por resolver. ¿Qué es el periodista y cuál es su función en la sociedad? ¿Existe un acuerdo común, al menos entre quienes la practican, de la definición de esa profesión? ¿Cómo se ve el periodista a sí mismo? ¿En qué medida los contenidos de las informaciones están influidos por lo que el periodista cree que es su papel? ¿Cuál es el contexto cultural y social en el que los periodistas buscan informaciones y elaboran las noticias que finalmente se publican o emiten?".

Diluido entre los avances tecnológicos, diluido en un mar de intereses espúreos a la profesión; diluido en un magma de abundantísima información; diluido en la escasez de prestigio y de credibilidad social; diluido en una falta de principios profesionales claros, el periodista se debate en una crisis de identidad profunda que puede llevar a la desaparición de la propia profesión, al menos, tal y como la conocemos hasta ahora.

\section{Método científico}

Señala Deizhandino (2005: 22) que "una de las cuestiones centrales de este nuevo siglo para las sociedades democráticas será la supervivencia o no de un periodismo independiente. La respuesta dependerá de si los 
periodistas tienen la claridad y convicción suficientes para articular lo que significa un periodismo independiente, y de si al resto de nosotros, como ciudadanos, nos importa", poniendo de manifiesto la importancia del problema y que las soluciones al mismo hay que buscarlas en dos dimensiones: los propios periodistas y la sociedad, en la que se incluyen no sólo a los ciudadanos individuales sino a las instituciones públicas cuya responsabilidad es fomentar y velar por los valores democráticos.

Por parte de los periodistas la respuesta a la crisis de identidad de la profesión debería venir por un doble camino: la profesionalización de la actividad, en el más amplio sentido del concepto, y el compromiso social, tanto con el receptor individual como con la sociedad en general.

Respecto a la profesionalización de la actividad, Kovack (2003: 103) recoge unas citas de Lippmann en las que propone que el periodismo debe recuperar, alcanzar un método científico en su quehacer ordinario: "El periodismo, declaró Lippmann, lo practicaban “testigos accidentales sin ninguna formación”. Las buenas intenciones, o lo que algunos podrían llamar "honrados esfuerzos" del periodista, no bastaban. La fe en el hosco individualismo del reportero más correoso, lo que Lippmann llamó el "cinismo del oficio”, tampoco. $\mathrm{Ni}$ algunas de las recientes innovaciones de la época, como los articulistas o los columnistas. La solución, sostuvo Walter Lippmann, consistía en que los periodistas tuvieran más “espíritu científico”. [...] Sólo existe una unidad posible en un mundo tan diverso como el nuestro. Más que la de objetivos, se trata de la unidad de método; la unidad del experimento disciplinado”. Lippmann quería decir con esto que el periodismo debería aspirar a "un método intelectual común y a un área de hechos válidos compartida”. Aunque aquélla era la época de la fe en la ciencia, Lippmann se hacía pocas ilusiones. "No importa que la información no sea susceptible de análisis matemático. De hecho, precisamente porque las noticias son un material complejo y resbaladizo, el buen periodismo exige el ejercicio de las virtudes científicas más destacadas".

Quizá sea el momento de recuperar estos planteamientos y dejar de pensar que el ejercicio del periodismo es la mera aplicación de unas técnicas que se transmiten de generación en generación, y proponer que el ejercicio del periodismo es una ciencia y, por lo tanto requiere un método científico. Como señala Fernández del Moral (1993: 32): "La única solución es profesionalizar la acción periodística de informar, profesionalizar la comunicación profundizando en un corpus científico específico, dándole sentido. Hacer de las ciencias de la información unas ciencias sociales en las que la teoría y la práctica se unan sinérgicamente para ofrecer soluciones reales. [...] La profesionalización comienza -o al menos debería comenzarprecisamente por ese camino, al reconocer la importancia en el mercado de la información de un trabajo que exige cada vez mayor creatividad y mayor pericia. Un mercado que debería tener recursos para todo, para esto no tiene el más mínimo reflejo y responde todavía de forma burda y balbuceante”. 
Esta concepción de la actividad periodística supone dejar para los románticos que el periodismo sea un oficio. Lo fue, pero en la actualidad su consideración debe ser distinta. Es una profesión con una amplia repercusión social que, para ejercerla bien, requiere unos amplios conocimientos y no sólo las destrezas y habilidades propias de un artesano. La actividad profesional del periodista tiene una enorme repercusión social y, por lo tanto, necesita la consideración de ser una de las profesiones más importantes, por su repercusión social, que existen en la sociedad. La actividad periodística tiene como misión dotar de contenidos (información, conocimiento) a los flujos de comunicación social, sea cuales sean los canales empleados. Acudiendo a la metáfora, no se trata de hacer trajes, se trata de vestir a la sociedad. Tener otra consideración de la actividad periodística es no tener claros los resortes imprescindibles de las sociedades democráticas. Otra cosa es que la realidad muestre lo contrario, pero eso no significa que no deba ser así; significa que los medios están realizando mal su misión. El problema no está en el deber ser, sino en el ser.

En este sentido, Zeller (2001: 123) mantiene que "la crisis de algunos actores centrales del campo periodístico ha puesto de manifiesto la necesidad de repensar la información periodística en relación con la vida pública y con el funcionamiento de la democracia en las sociedades de capitalismo avanzado. La actividad de los medios de comunicación se ha convertido en una de las piezas más dinámicas de la industria cultural y, más importante aún, en un factor clave de la estructuración de la vida social y política”.

En muchas ocasiones se identifica a la profesión periodística con destrezas para elaborar un mensaje y en habilidades para plasmarlo en un soporte. Pero la actividad periodística no consiste sólo en eso, aunque sean sus herramientas imprescindibles. La parte más importante de la actividad periodística es la generación de contenidos, entendida como capacidad para analizar la realidad, priorización de los hechos, metodología en la elaboración del mensaje, control de calidad de los mismos y valores en el compromiso social. En este sentido daría lo mismo el medio o el canal que se emplease para transmitir a la sociedad ese contenido. La razón de ser del periodismo no deriva de emplear un medio, sino de la metodología de elaboración del mensaje. Como señaló David Simon (2009) en las sesiones celebradas en el Senado de los Estados Unidos, "un vecino que escucha con atención y se preocupa por la gente es un buen vecino, no tiene nada que ve con un asistente social. De la misma manera que un vecino con una manguera de riego para el jardín y con buenas intenciones no es un bombero. Pensar otra cosa es un insulto a los asistentes sociales y a los bomberos".

\section{6. Ética de la calidad}

Una profesión necesita una deontología profesional que la sustente. Un corpus que diga lo que está bien y lo que está mal hecho. No sólo de cara a consideraciones morales o a consideraciones éticas personales. Es 
necesario que se implanten unos criterios deontológicos que sustenten la calidad del quehacer periodístico, la calidad de los contenidos que se oferten y la calidad de los fines empresariales que se persigan. Soria (1989: 49) establece tres niveles de la guía de los actos humanos e informativos: "Se llama Ética cuando comprende todos los aspectos personales de los actos; Deontología cuando se refiere a los aspectos específicos profesionales, y Derecho cuando afecta a los aspectos comunitarios, por tanto externos y normalmente coactivos". Es en ese segundo nivel en el que habría que consolidar unos principios de calidad pactados entre empresas periodísticas y sociedad.

Refiriéndose a este tema, Sinova (2003: 174) dice que necesitamos "una bien definida ética profesional e informativa, que no sólo recoja los tradicionales deberes de los periodistas sino también las demandas que plantea una sociedad de las libertades cada día más desarrolladas, más exigentes y más necesitada de una información completa, veraz y útil. El periodista, como consecuencia de estas exigencias, se enfrenta hoy a retos cada vez más altos, que le reclaman una mejor formación técnica y ética para poder dar una respuesta más compleja y más útil. Si la información es una necesidad y un derecho, y se erige además en uno de los presupuestos de la democracia, la información no puede quedar al arbitrio de quienes no tengan bien clara la dimensión pública de su tarea".

Por ello, un planteamiento elemental de la ética periodística hoy debe ocuparse de varias cuestiones básicas e insoslayables: entre ellas, el tributo profesional a la verdad informativa, el reconocimiento del protagonismo de los destinatarios de la comunicación social, con todas las consecuencias que origina, y la responsabilidad pública del periodista.

Pero no solo desde el punto de vista de la ética social, sino también desde el punto de vista empresarial. Señala Hernández (1997: 172) que "en los últimos años, la discusión sobre la calidad y su control ha pasado, de ser algo extraño y complicado, propio de ingenieros encargados de complicados procesos industriales a ocuparse también de las empresas de servicios hasta convertirse en algo cotidiano. No resulta extraño hoy en día encontrarse en cualquier establecimiento, ya sea un banco, una estación de tren, un hotel o una agencia de relaciones públicas, con una encuesta de satisfacción del cliente, con una declaración de misión o con la noticia de que cualquier empresa ha obtenido la certificación para la calidad según la normativa internacional ISO 9000.

Sin embargo, con la única excepción de algunas empresas de comunicación empresarial y relaciones públicas, la empresa informativa parece encontrarse muy lejos de este movimiento tan generalizado. A simple vista, da la impresión de que, sobre todo, los medios impresos se encuentran en las antípodas de cualquier reflexión acerca de sus propios procesos. Cómo mejorarlos y cómo acercarse al cliente y a sus necesidades. 
La inercia parece ser la única fuerza motriz que afecta a la mayor parte de la prensa escrita, en especial la diaria. A pesar de que los cambios tecnológicos, demográficos y del panorama informativo ponen en entredicho todos los días la organización de los diarios, el inmovilismo parece la única respuesta”. Para concluir que "es necesario, sin embargo, seguir avanzando en la definición de unos estándares de calidad para los medios de comunicación. Unos estándares que vayan más allá de la dicotomía entre medios populares y medios de calidad y que permitan seguir profundizando en estas cuestiones y superar planteamientos desfasados".

Esos estándares de calidad de la actividad periodística deberían englobar varias cuestiones:

- $\quad$ Calidad de la misión, fines, objetivos y estrategias de las empresas que sustentan la actividad periodística. Calidad como adecuación a los principios básicos de dicha actividad. La actividad periodística tiene unos factores constituyentes que la empresa que se dedique a ella tiene que asumir, respetar y garantizar, y no al revés. Harold Evans lo dijo de una manera muy gráfica: "Hacer periódicos no es, ni será, como producir judías en lata”. Dicha afirmación es aplicable a toda empresa, o grupo mediático, que gestione cualquier medio de comunicación que se dedique a la actividad periodística. Porque, como señala Sinova (2003: 178), "la empresa está también condicionada, como el periodista, por el derecho a la información, afectada por los mismos deberes que tiene el periodista. La empresa informativa está obligada, por ejemplo, igual que el periodista, a la verdad, que no puede quedar supeditada a su programa ideológico o editorial; está obligada, igual que el periodista, a servir a las necesidades informativas de los públicos. Lo que quiere decir que debe ofrecerle información imparcial de los hechos relevantes aunque no le gusten; está obligada, igual que el periodista, a prestar audiencia a los públicos".

- $\quad$ Calidad de los productos informativos, tanto en sus contenidos como en sus formatos. En este punto juega un papel importante el método científico que debe emplear el periodista a la hora de elaborar contenidos. Dicho método asegurará que sus informaciones poseen la calidad necesaria, ya que responden a una manera de hacer, que ha sido experimentada y acrisolada lo suficiente.

- Calidad en los controles de calidad. Cualquier gestión que se precie tiene en su haber unos puntos de control que aseguran que los productos que oferta al mercado tienen una calidad suficiente. ¿Por qué las empresas dedicadas a la generación de información periodística carecen de los mismos? Controles que aseguren que los contenidos que ponen en circulación en los flujos comunicacionales sociales tienen la calidad suficiente como para ser considerados como tales. 
Teniendo en cuenta lo que pone de manifiesto Sánchez Tabernero (1997: 230) al afirmar que "no es casual que muchas de las empresas de comunicación que proporcionan contenidos de mayor calidad y ganan más dinero pertenezcan a sociedades sin ánimo de lucro, o al menos, en su cultura directiva el lucro no constituya un factor dominante. La falta de presión para lograr más beneficios ha permitido a estas compañías invertir en calidad un poco más que sus competidores; de este modo, han alcanzado prestigio y se han ganado la confianza del público”.

\section{Compromiso con los ciudadanos}

Ahora bien, todo esto no tendría mucho sentido si los medios de comunicación, los periodistas y las empresas en las que realizan su actividad no tuviesen un compromiso social. Un compromiso con los ciudadanos que Kovach (2003: 73) lo describe como "un pacto tácito con el lector, oyente o espectador que le dice que las críticas cinematográficas, por ejemplo, son sinceras, que las reseñas de restaurantes no se dejan influenciar por los anunciantes, que las noticias no responden a intereses particulares ni son sesgadas. La idea de que las personas que nos informan no sufren impedimentos obstruccionistas para investigar o decir la verdad -ni siquiera a expensas de los intereses económicos de los propietarios del medio en cuestión- es un requisito previo a contar una noticia no sólo de manera veraz, sino convincente. Es el elemento fundamental para que los ciudadanos crean en un determinado medio de comunicación. Es la fuente de su credibilidad. Es, en definitiva, el mejor activo de un medio informativo y de aquellos que trabajan para él”.

Pacto que no siempre ha sido mantenido por los medios y, en su tarea informativa, se han dejado llevar por otros intereses distintos al informativo. Los ciudadanos lo han detectado y se han alejado de los medios. Señala Kovach (2003: 95) que "a los periodistas les gusta pensar que son los representantes del pueblo, los encargados de ocupar el puesto de vigía de la sociedad por el bien del ciudadano. Es cada vez mayor, sin embargo, el número de ciudadanos que no creen en ellos. La gente ve sensacionalismo, explotación, y piensa que los periodistas trabajan por dinero, por la fama o, y esto es quizá peor, por una especie de gozo perverso con la infelicidad".

Con este alejamiento entre la sociedad y los medios, la actividad periodística ha perdido su activo más importante: la credibilidad. Al no ejercitar el compromiso social con los ciudadanos y devenir más en actividades comerciales, la sociedad les ha dado la espalda. Los ciudadanos han dejado de considerar a los medios de comunicación como canales imprescindibles por los que reciban la información necesaria para comprender el mundo en el que viven y, como consecuencia, cada día los utilizan menos y buscan en otros canales esa información necesaria para su quehacer social. 
Recuperar ese compromiso social y explicitarlo, día a día, es una tarea primordial de los medios si quieren recuperar su credibilidad y con ella a la ciudadanía. Compromiso social que no afecta sólo a los periodistas, afecta también a los propietarios de los medios y a los propios directivos, que no han de orientar su gestión a la mera consecución de objetivos comerciales sino que los deben posponer a sus compromisos sociales.

En este sentido, Kovach (2003: 123) establece cinco principios básicos:

1. El propietario/la empresa debe comprometerse en primer lugar con el ciudadano.

2. Contratar directivos que también pongan el ciudadano en primer lugar.

3. Establecer y declarar conceptos básicos claros.

4. Los periodistas tienen la última palabra sobre las noticias.

5. Comunicar al lector criterios claros. "Para recuperar el contacto del ciudadano con la información, y a través de ella con el mundo, el periodismo debe restablecer el compromiso con el pueblo que la industria periodística ha contribuido de manera tan errónea a subvenir".

Sin ese compromiso social las empresas periodísticas, la experiencia así lo demuestra, pierden sus mercados y con ellos sus beneficios económicos y se acentúa la crisis de los medios como estructuras empresariales. Por eso se hace cada vez más necesario que los medios de comunicación expliciten ese pacto tácito que tienen con sus audiencias sobre lo que les quieren ofrecer y ellos demandan. Ese pacto tácito se ha diluido sobre manera y los ciudadanos consideran que los medios de comunicación no defienden sus intereses sociales, sino que se dedican a defender sus propios intereses económicos o políticos. Si los medios de comunicación quieren recuperar a la ciudadanía y con ella la consideración social que en épocas anteriores tuvieron, por necesidad, han de volver a pactar con los ciudadanos ese compromiso de defender los valores sociales y, lo han de demostrar día a día. Y, también, los periodistas, individualmente.

Porque la solución al problema del periodista diluido no va a venir de la mano de solucionar los problemas de los medios de comunicación como estructuras de negocio. Por más que como señala Bennett (2010: 46) "hoy en día, muchos de los periodistas más ilustres pasan más tiempo pensando en los nuevos modelos de negocio del periodismo que en los nuevos modelos de periodismo”.

La solución a los problemas de los medios de comunicación hay que encontrarla en esos nuevos modelos de hacer periodismo basados en una metodología científica de elaboración de contenidos, en una definición clara del producto que ofertan, en unos criterios de calidad para los contenidos, en recuperar el compro- 
miso social que tiene el periodista con el ciudadano de ofertarle una información que le ayude a comprender el mundo en el que vive y en una gestión empresarial que priorice el interés social por encima de los intereses comerciales. En definitiva, "como decía Kay Graham, que tanto respetaba y quería a Leo Bogart, lo único que importa es hacer del buen periodismo un magnífico negocio” (Giner, 2008). Y no al revés.

\section{Referencias bibliográficas}

Almirón Roig, N. (2006): “Los valores del periodismo en la convergencia digital: civic journalism y quinto poder”, Revista Latina de Comunicación Social, 61. [Disponible en: http://www.revistalatinacs.org/200609Almiron.htm. Consultado el 204-2007].

Artz, L. y Kamalipour, Y. (eds.) (2003): The Globalization of Corporate Media Hegemony. Nueva York: Suny Press.

Arriaza Ibarra, K. (2008): "La transformación de los medios públicos europeos en la nueva era digital”, Área Abierta, n. 20, julio 2008. [Disponible en: http://revistas.ucm.es/inf/15788393/articulos/ARAB0808230001A.PDF Consultado el $10 / 3 / 2010]$.

Baldessar, M. J. (2007): “Consideraciones sobre las mudanzas necesarias en el periodismo y en la formación profesional a partir de Internet”, Global Media Journal, vol. 4, n. 7, pp. 112-118. [Disponible en: http://www.gmjei.com/journal/ index.php/GMJ_EI/issue/view/15. Consultado el 13/3/2008).

Bennett, P. (2010): “¿Qué va quedando y qué seguirá cambiando en el mundo de los medios periodísticos?”, Cuadernos de Periodistas, n. 19, marzo 2010, pp. 37-52.

Canel, M. J. y Sádaba, T. (1999): “La investigación académica sobre las actitudes profesionales de los periodistas. Una descripción del estado de la cuestión”, Comunicación y Sociedad, n. 2, pp. 9-32.

Canga Larequi, J. (2001): “Periodismo e Internet: nuevo medio, vieja profesión”, Estudios sobre el Mensaje Periodístico, n. 7, pp. 33-48.

Cebrián Herreos, M. (2002): “Expansión e incertidumbres de la radio”, Telos. Cuadernos de Comunicación, n. 51, abril-junio.

Delporte, C. (1999): Les Journalistes en France 1880-1950. París: Seuil.

Diezhandino Nieto, M. P. (2005): “España: Periodistas y medios de comunicación en el escenario del siglo XXI. Que la esperanza sea lo último que se pierda", Telos, Cuadernos de Comunicación e Innovación, n. 63, abril-junio. [Disponible en: http://sociedadinformacion.fundacion.telefonica.com/telos/articulocuaderno.asp @idarticulo=1\&rev=63.htm. Consultado el 23/7/2008].

Evans, H. (2009): El País, 12-2-2009. 
Fernández del Moral, J. (1993): "La mercantilización de la información periodística”, Comunicación y Sociedad, n. 1 y 2 , pp. 29-37.

Garrison, B. (1995): Computer-assisted reporting. New Jersey: Laurence Erlbaum Associates.

Giner, J. A. (2008): "Siete lecciones que explican la anunciada crisis de los diarios norteamericanos", Cuaderno de Periodistas, n. 15, septiembre, pp. 45-51.

Hernández Muñoz, R. (1997): "Avances en la búsqueda de un sistema de calidad para las redacciones de los diarios", Comunicación y Sociedad, n. 1, pp. 169-192.

Hallin, D. (1997): “Comercialidad y profesionalismo en los medios periodísticos estadounidenses”, CIC, n. 3, pp. 123-144.

Kovach, B. y Rosenstiel, T. (2003): Los elementos del periodismo. Madrid: Ediciones El País.

Labio Bernal, A. (2008): “Periodismo de entretenimiento: la trivialización de la prensa de referencia”, Estudios sobre el Mensaje Periodístico, n. 14, pp. 435-447.

Martínez, L. (2005): "El periodista en transformación en el ciberespacio: la reivindicación del periodista como periodificador de la red", Razón y Palabra, n. 42, [Disponible en: http://www.razonypalabra.org.mx/anteriores/n42/lmartinez. html Consultado el 26/6/2006].

Mateos-Pérez, J. (2009): “La información como espectáculo en el nacimiento de la televisión privada española (1990-1994)", Estudios sobre el Mensaje Periodístico, n. 15, pp. 315-334.

McChesney, R. (ed.) (2005): The Future of Media. Resistance and Reform in the 21st Century. Nueva York: Seven Stories Press.

Nobre-Correia, J. M. (2006): “La crisis del periodismo. Cierta muerte anunciada”, Telos. Cuadernos de Comunicación e Innovación, n. 66, enero-marzo, 2006. [Disponible en: http://sociedadinformacion.fundacion.telefonica.com/telos/ articuloperspectiva.asp@ idarticulo=1\&rev=66.htm. Consultado el 23/6/2007].

Ortega, F. (2003): “Los retos del periodismo”, Telos, Cuadernos de Comunicación e Innovación, n. 54, enero-marzo 2003. [Disponible en: http://sociedadinformacion. fundacion.telefonica.com/telos/articulocuaderno.asp@idarticulo=2\&rev $=54 . h t m$. Consultado el 21/6/2005].

- (2007): “Un periodismo que va a la deriva”, Razón y Palabra, n. 55, febrero-marzo, 2007, México. [Disponible en: http://www.razonypalabra.org.mx/anteriores/n55/ fortega2.html Consultado el 21/6/2006].

Ortega, F., Humanes, Mª L.(2000): Algo más que periodistas. Barcelona: Ariel.

Ramonet, I. (2005): “Medios de comunicación en crisis", Le Monde Diplomatique, (Opinión), 3-01-2005. [Disponible en:http://www.rebelion.org/noticias/2005/1/9510.pdf Consultado el 28/6/2006].

Reddik, R., King, E. (1995): The online journalism: using the internet and other eletronic resources. Fort Worth, Texas: Harcourt Brace. 
Salaverría, R. y García Avilés, J. A. (2008): “La convergencia tecnológica en los medios de comunicación: retos para el periodismo", Trípodos, n. 23, pp. 31-47.

Sánchez-Tabernero, A. (1997): "Reflexiones sobre la gestión de la calidad en empresas de comunicación”, Comunicación y Sociedad, n. 1, pp. 203-239.

Singer, J. B. (2004): “Strange bedfellows? The diffusion of convergence in four news organizations", Journalism Studies 5 (1), pp. 3-18.

- (2006): "Partnerships and Public Service: Normative Issues for Journalists in Converged Newsrooms", Journal of Mass Media Ethics, 21 (1), pp. 30-53.

Simon D. (2009): Intervención citada por Felipe Sahagún en “El futuro del periodismo”, Cuadernos de Periodistas, n. 17, julio, Madrid: APM.

Sinova, J. (2003): “Acerca de la responsabilidad pública del periodista. La verdad, los derechos de los públicos y otras exigencias del trabajo informativo”, Doxa Comunicación, n. 1, 2003. pp. 171-184.

Suárez Villegas, J. C. (2009): “La crisis de identidad del periodista y la ética profesional”, Estudios sobre el Mensaje Periodístico, n. 15, pp. 119-134.

Soria, C. (1989): La crisis de identidad del periodista. Barcelona: Mitre.

Zeller, C. (2001): “Los medios de comunicación y la formación de la voz de la sociedad democrática”, Anàlisi, n. 26. 